\title{
Isolation and growth characteristics of an EDTA-degrading member of the $\alpha$-subclass of Proteobacteria
}

\author{
Hans-Ueli Weilenmann, Barbara Engeli, Margarete Bucheli-Witschel \& Thomas Egli* \\ Department of Environmental Microbiology and Molecular Ecotoxicology, Swiss Federal Institute for \\ Environmental Science and Technology (EAWAG), Überlandstr. 133, 8600 Dübendorf, Switzerland (*author \\ for correspondence: e-mail: egli@eawag.ch)
}

Accepted 21 April 2004

Key words: aerobic degradation, bacterial strain DSM 9103, complexing agents, EDTA, Rhizobiazeae group, taxonomy

\begin{abstract}
A Gram-negative, ethylenediaminetetraacetic acid (EDTA)-degrading bacterium (deposited at the German Culture Collection as strain DSM 9103) utilising EDTA as the only source of carbon, energy and nitrogen was isolated from a mixed EDTA-degrading population that was originally enriched in a column system from a mixture of activated sludge and soil. Chemotaxonomic analysis of quinones, polar lipids and fatty acids allowed allocation of the isolate to the $\alpha$-subclass of Proteobacteria. 16S rDNA sequencing and phylogenetic analysis revealed highest similarity to the Mesorhizobium genus followed by the Aminobacter genus. However, the EDTA-degrading strain apparently forms a new branch within the Phyllobacteriaceae/ Mesorhizobia family. Growth of the strain was rather slow not only on EDTA $\left(\mu_{\max }=0.05 \mathrm{~h}^{-1}\right)$ but also on other substrates. Classical substrate utilisation testing in batch culture suggested a quite restricted carbon source spectrum with only lactate, glutamate, and complexing agents chemically related to EDTA (nitrilotriacetate, iminodiacetate and ethylenediaminedisuccinate) supporting growth. However, when EDTAlimited continuous cultures of strain DSM 9103 were pulsed with fumarate, succinate, glucose or acetate, these substrates were assimilated immediately. Apparently, the strain can use a broader spectrum than indicated by traditional substrate testing techniques. The EDTA species CaEDTA and MgEDTA served as growth substrates of the strain because in the mineral medium employed EDTA was predicted to be mainly present in the form of these two complexes. The bacterium was not able to degrade $\mathrm{Fe}^{3+}$-complexed EDTA.
\end{abstract}

\section{Introduction}

In a variety of industrial processes as well as in industrial and household products complexing agents are used to sequester and mask metal ions in order to prevent the deleterious effects of free metal ions. Thus, complexing agents are produced and applied in large quantities. Worldwide, the most frequently employed complexing agents are di- and triphosphates, which are essential components of laundry detergents (Egli 1988). In addition, hydroxycarboxylates (e.g., citrate), phosphonates and particularly aminopolycarboxylic acids are extensively used in industrial processes and products (Potthoff-Karl et al. 1996). Within the latter group, ethylenediaminetetraacetic acid (EDTA) and nitrilotriacetic acid (NTA) are the predominant chemicals followed by diethylenetriaminepentaacetic acid (DPTA) and hydroxyethylethylenediaminetriacetic acid (HEDTA).

Today the quantity of EDTA employed worldwide amounts to some 103,000 of metric tons per year (calculated as $\mathrm{H}_{4}$ EDTA for 1993; Könen 
1997) and its fields of application are plentiful, ranging from photographic industry, as galvanic industry, for textile and paper manufacturing, for the decontamination of nuclear power installations, as a component of fertilisers and industrial cleaners, to additives in cosmetics and food products (Potthoff-Karl et al. 1996; Wolf \& Gilbert 1992).

Due to its mainly water-based applications EDTA is normally released into wastewater. However, in conventional wastewater treatment plants EDTA is neither biologically degraded nor is it known to sorb onto activated sludge (Alder et al. 1990; Gardiner 1976; Kari \& Giger 1996; Saunamäki 1995). Up to now, there is merely one report on the efficient EDTA elimination of about $80 \%$ in an industrial wastewater treatment plant (Kaluza et al. 1998). Also in natural systems EDTA has been observed to be rather recalcitrant towards chemical or biological degradation leading to high EDTA concentrations measured in surface waters that range from about 10 to $100 \mu \mathrm{g}^{-1}$ ( Houriet 1996; Klopp \& Pätsch 1994; Könen 1997). Only the Fe(III)EDTA complex was shown to be photolabile and degradable by sunlight (Kari 1994). On sunny days, this process can contribute to EDTA elimination in rivers.

All in all, EDTA has become a concern in recent years, especially because of its possible contribution to the mobilisation of heavy metal ions deposited in river sediments and soils. In Germany, for instance, the government and representatives of industry published a statement announcing the intention to reduce EDTA pollution of aquatic systems by 50\% (BMU 1991). A reduction can be achieved with a number of measures such as recycling of EDTA in industrial processes or by replacing EDTA by other more easily degradable complexing agents such as NTA or EDDA (Sykora et al. 2001). In addition, ethylenediaminedisuccinate (EDDS), a structural isomer of EDTA of biological origin, has been proposed to substitute EDTA in some applications (Kovaleva et al. 1992). In case of two processes, i.e. pulp making and radionuclide decontamination, it has been shown, at least theoretically, that EDDS should be more or less equivalent to EDTA in terms of efficacy (Jones \& Williams 2001).

Alternatively, also physicochemical and biological techniques for the elimination of EDTA from industrial wastewaters have received atten- tion. To establish biological treatment processes the availability of suitable microbial strains capable to degrade EDTA is required. To date, only two EDTA-consuming pure bacterial cultures have been described in detail, namely Agrobacterium radiobacter ATCC 55002 (Lauff et al. 1990) and strain BNC1 (Nörtemann 1992). Here we describe the isolation of a third EDTA-utilising strain and its physiological and taxonomic characterisation.

\section{Material and methods}

\section{Media and culture conditions}

The strain was cultivated at $30{ }^{\circ} \mathrm{C}$ in batch or continuous culture with a mineral salts medium already employed for the isolation of NTA-utilising bacteria (Egli et al. 1988). It was supplemented with carbon and nitrogen sources as indicated for the individual experiments and the $\mathrm{pH}$ was adjusted to 7.0. The mineral medium contained $1.0 \mathrm{~g} \mathrm{l}^{-1} \mathrm{MgSO}_{4} \cdot 7 \mathrm{H}_{2} \mathrm{O}, 0.2 \mathrm{~g}^{-1} \mathrm{CaCl}_{2} \cdot 2 \mathrm{H}_{2} \mathrm{O}$, $0.13 \mathrm{~g} \mathrm{l}^{-1} \quad \mathrm{KH}_{2} \mathrm{PO}_{4}$ and $0.615 \mathrm{~g} \mathrm{l}^{-1} \quad \mathrm{Na}_{2} \mathrm{HPO}_{4}$. Two milliliter of Widdel trace element solution (Pfennig et al. 1981) and $1 \mathrm{ml}$ of a vitamin solution (Egli et al. 1988) were added to 11 of mineral medium.

Continuous cultivation of the EDTA-degrading strain was performed in bioreactors (MBR, Switzerland, 21 working volume and Bioengineering, Switzerland, 2.51 working volume), in which the $\mathrm{pH}$ was maintained at 7.0 by automatic addition of $\mathrm{H}_{3} \mathrm{PO}_{4}(1.0 \mathrm{M})$. The culture was stirred at $1000 \mathrm{rpm}$ and aerated at a rate of $0.1 \mathrm{vvm}$. Batch growth experiments to determine maximum specific growth rates and to observe growth with mixtures of complexing agents were carried out in 11 Erlenmeyer flasks containing initially 0.51 medium being aerated by vigorous stirring with a magnetic fly.

Characterisation of the EDTA-degrading bacterial isolate

Gram staining, aminopeptidase and oxidase tests were performed using standard methods. For metabolic profiling the API test stripes 20NE, 20E and $50 \mathrm{CH}$ (Bio Mérieux, France) were employed. The GC content, the quinone pattern and the 
polar lipid and fatty acid composition was analysed by DSMZ (Germany). Also 16S rDNA sequencing, sequence comparison and presentation of the results as phylogenetic tree and similarity matrix was carried out by DSMZ.

\section{Biomass determination}

Biomass was routinely monitored as optical density (OD) at $546 \mathrm{~nm}$ with the help of an Uvikon 860 spectrophotometer (Kontron, Switzerland). As during growth with EDTA insoluble precipitates were formed the culture liquid was acidified with a few microliters of concentrated $\mathrm{HCl}$ prior to the determination of OD. Additionally, biomass was quantified gravimetrically as dry weight (DW) by filtration of cell suspension through a $0.2 \mu \mathrm{m}$ pore size polycarbonate membrane filter (Nuclepore, USA). Cells collected on filters were washed with acidified distilled water and were dried at $105{ }^{\circ} \mathrm{C}$ to constant weight.

Analysis of dissolved organic carbon (DOC) and substrate concentrations in the cultivation liquid

Prior to analysis cells were removed from the cultivation liquid either by centrifugation $(5 \mathrm{~min}$, $20,000 \times g$ ) or by filtration through a $0.2 \mu \mathrm{m}$ pore size polyvinylidene difluorid membrane filter (Millipore, USA) and the cell-free sample was then used for determination of the following parameters.

\section{DOC}

The filtrate was appropriately diluted with distilled, carbon-free water and the solution was acidified with one drop of $\mathrm{HCl} 32 \%$. After stripping dissolved $\mathrm{CO}_{2}$ with $\mathrm{N}_{2}$ gas DOC was measured with a TOCOR 2 total organic carbon analyser (Maihak AG, Germany).

\section{EDTA and [S,S]-EDDS}

These two compounds were measured as the iron(III)-complex by HPLC with a Lichrochart 250-4 C18 column (Merck, Germany) as described previously by Witschel \& Egli (1998). The eluent consisted of a formate buffer ( $5 \mathrm{mM}$ sodium formate, $15 \mathrm{mM}$ formic acid, $2 \mathrm{mM}$ tetrabutylammonium bromide) and contained $12.5 \%$ methanol.
NTA and fumarate

Both polycarboxylic acids were analysed by HPLC using a HPICE-AS1 ion exclusion column (Dionex, USA) following a method described by Schneider et al. (1988).

$N, N^{\prime}-E D D A$

$\mathrm{N}, \mathrm{N}^{\prime}$-EDDA was analysed as the $\mathrm{Cu}(\mathrm{II})$-complex by HPLC with a Lichrochart 250-4 $100 \mathrm{NH}_{2}$ column (Merck) by the method of Klüner (1996). The eluent contained $1.0 \mathrm{mM}$ cupric acetate plus $0.17 \mathrm{M}$ acetic acid, with the $\mathrm{pH}$ adjusted to 5.1 with $\mathrm{NaOH}$.

$I D A$

IDA concentrations were measured by HPLC with a HPIC AS11 anion exchange column (Dionex). For separation a $\mathrm{NaOH}$ gradient was employed increasing from initially $2.5 \% \mathrm{NaOH}(95 \mathrm{mM})$ to $7.5 \% \mathrm{NaOH}(95 \mathrm{mM})$ within 6 min at a flow rate of $1 \mathrm{ml} \mathrm{min}-1$. IDA was detected by a Dionex CD20 conductivity detector.

\section{Analysis of nitrogenous compounds}

Ammonium concentrations were measured according to the indophenol method described by Scheiner (1976). Rapid determination of the ammonium concentration in the bioreactor cultivation liquid was performed with analytical test strips provided by Merck.

Nitrate and nitrite were analysed simultaneously with the help of an automated ion analyser (Skalar, The Netherlands).

\section{Chemicals}

[S,S]-EDDS was a gift of the laboratory of Prof. H. Zähner (Tübingen, Germany). All other chemicals were of analytical grade and were purchased from either Fluka (Switzerland) or Merck.

\section{Results}

Isolation of an EDTA-degrading strain

\section{Description of the inoculum}

The inoculum for the isolation of an EDTAdegrading bacterial strain was obtained from N. Gschwind (Ciba-Geigy, Schweizerhalle, 
Switzerland). It was a mixed microbial culture enriched in a column packed with activated carbon that was continuously fed with a mineral medium containing EDTA as sole source of carbon, nitrogen and energy. The column was originally inoculated with activated sludge from various industrial wastewater treatment plants and with soil extracts. In the mixed population selected EDTA degradation with concomitant nitrate production was observed (Gschwind 1992).

\section{Further enrichment on a column}

A column packed with glass beads was inoculated with the mixed culture above described. The column was aerated and fed with a mineral salt medium described in Materials and methods containing between 200 and $300 \mathrm{mg} \mathrm{l}^{-1}$ EDTA as only source of carbon and nitrogen. The medium was circulated and the DOC concentration in the liquid was followed routinely. When it indicated that EDTA was nearly consumed fresh EDTA was added to the medium.

\section{Enrichment in suspended batch cultures}

After about half a year of continuous enrichment in the glass bead column system EDTA degradation became stable and reproducible. Material from the column was then used as inoculum for batch cultures. The same EDTA-containing medium as in the column enrichment was used. Since the cells flocculated strongly in batch culture several improvements of the culture conditions were introduced: First the $\mathrm{Ca}^{2+}$ concentration in the medium was doubled. Second, the $\mathrm{pH}$ optimum and temperature optimum as well as the optimum EDTA concentration for growth were determined. The mixed culture grew best at slightly basic $\mathrm{pH}$ values (optimum between $\mathrm{pH} 7.5$ and 8.5 ) and at a temperature of $30-32{ }^{\circ} \mathrm{C}$. Initial EDTA concentrations of $1-2 \mathrm{~g}^{-1}$ did not inhibit growth of the enriched bacterial community. Based on these results the following growth conditions for EDTA degraders were chosen for further experiments: $T=30{ }^{\circ} \mathrm{C}$, initial EDTA concentration in the range of $1-1.5 \mathrm{~g} \mathrm{l}^{-1}, \mathrm{CaCl}_{2} \cdot 2 \mathrm{H}_{2} \mathrm{O}$ concentration in the mineral medium of $0.4 \mathrm{~g} \mathrm{l}^{-1}$, and an initial $\mathrm{pH}$ of 7.0. Instead of slightly basic initial $\mathrm{pH}$ of the medium a neutral $\mathrm{pH}$ was chosen because during consumption of EDTA pH increased anyhow.
As a consequence, the mixed culture grew faster and did not flocculate any more. Concomitantly with the consumption of EDTA biomass was formed and nitrate accumulated in the medium. Only a small increase of ammonium and nitrite concentrations in the culture liquid was observed. About $60 \%$ of the EDTA-nitrogen were found in the form of inorganic nitrogen compounds at the end of the cultivation period. The accumulation of nitrate instead of ammonium suggested the presence of nitrifying bacteria in the mixed community, which oxidised the $\mathrm{NH}_{4}^{+}$excreted by the EDTA-degrader.

Isolation of a pure EDTA-degrading strain from suspended batch cultures

Cells from batch cultures were diluted in phosphate buffer ( $\mathrm{pH}$ 7.2) and plated on Plate Count Agar (PCA). From PCA plates single colonies were picked and grown in liquid culture with an optimised mineral medium containing EDTA. Direct plating on selective EDTA agar plates was not successful because colony growth was too slow. This procedure was repeated until a pure culture was obtained. The pure EDTA-degrading strain was deposited at the German Culture Collection under the number DSM 9103.

The maximum specific growth rate, $\mu_{\max }$, of strain DSM 9103 with EDTA as the only source of carbon, nitrogen and energy (initial concentration of $850 \mathrm{mg}$ EDTA $1^{-1}$ ) at $\mathrm{pH} 7.0$ and $T=30{ }^{\circ} \mathrm{C}$ was $0.05 \pm 0.006 \mathrm{~h}^{-1}$. EDTA was utilised down to a final concentration below $5 \mathrm{mg} \mathrm{l}^{-1}$. Relating measured DOC concentrations to those of EDTA indicated that no carbonaceous products accumulated to a significant extent during growth with EDTA. However, surplus nitrogen stemming from EDTA accumulated in the culture liquid in the form of ammonium and reached a final concentration of about $90 \mathrm{mg}$ $\mathrm{NH}_{4}^{+} 1^{-1}$ (Figure 1). The growth yield, $Y_{\mathrm{x} / \mathrm{s}}$, for EDTA was $0.26 \pm 0.01 \mathrm{~g} \mathrm{DW}\left(\mathrm{g} \mathrm{EDTA}^{-1}{ }^{-}\right.$. Both the specific growth rate and the yield of DSM 9103 on EDTA were similar to those reported for growth of the EDTA-degrading strain BNC1 under similar conditions, which were $\mu_{\max }=0.03-$ $0.07 \mathrm{~h}^{-1}$ and $Y_{\mathrm{x} / \mathrm{s}}=0.271 \mathrm{~g}$ DW $(\mathrm{g} \text { EDTA })^{-1}$, respectively (Henneken et al. 1994, 1998). No growth of strain DSM 9103 with EDTA was observed under denitrifying conditions. 


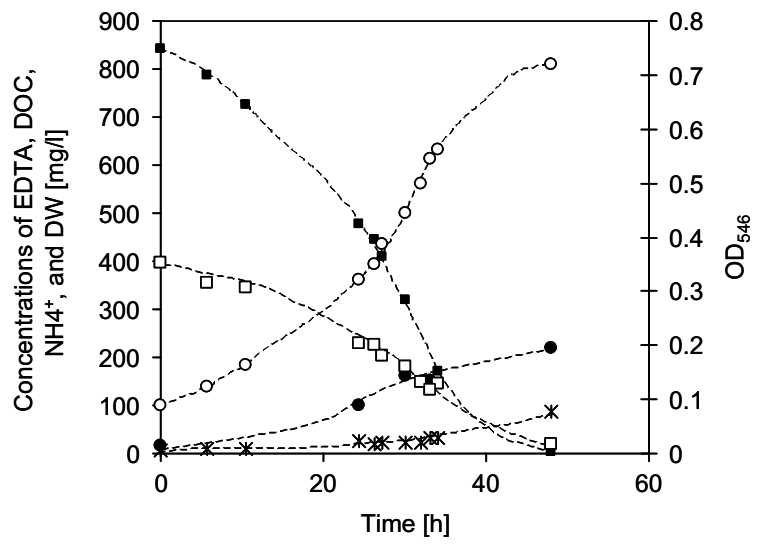

Figure 1. Batch growth of strain DSM 9103 with EDTA as sole source of carbon, nitrogen and energy. The biomass concentration in the cultivation liquid was monitored as DW $(\bullet)$ and $\mathrm{OD}_{546}(\mathrm{O})$. In addition, the consumption of EDTA $(\boldsymbol{\square})$, the excretion of $\mathrm{NH}_{4}^{+}$ $(\star)$ as well as the development of DOC $(\square)$ were recorded.

\section{Characterisation of strain DSM 9103}

Strain DSM 9103 was a Gram-negative, non-motile, rod-shaped bacterium. The short rods were often found as pairs under the microscope (Figure 2). It formed small white colonies on EDTA plates. According to results from the API test stripes the strain is urease and oxidase positive and can transform esculin. All other API tests were negative or not clearly positive. Neither under aerobic nor under fermenting conditions was growth observed with the carbon sources offered in the API 20NE, 20E and $50 \mathrm{CH}$ stripes. Also growth tests in test tubes using liquid mineral medium amended with various carbon substrates were negative despite extended periods of incubation for up to 2 months. Only lactate and glutamate indicated scanty growth. However, slow but good growth, was observed on complex medium at low concentrations, such as Plate Count Broth at one third of the normal strength. Moreover, pulsing of carbon sources into a continuous culture of strain DSM 9103 growing with EDTA as sole source of carbon, nitrogen and energy $\left(D=0.035 \mathrm{~h}^{-1}\right)$ showed that the bacteria were able to immediately utilise glucose, acetate,

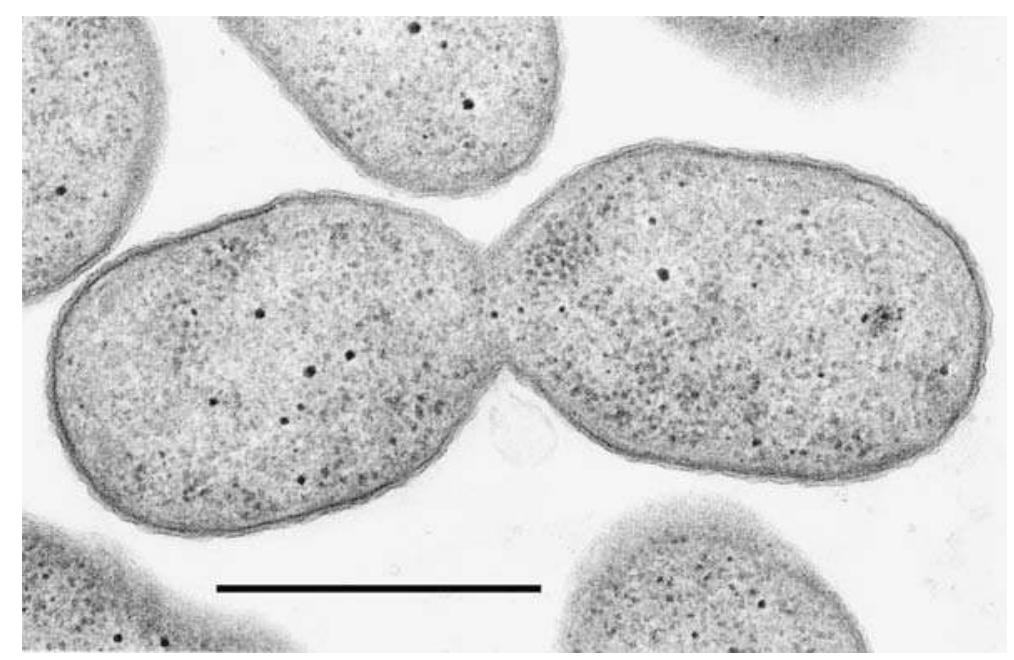

Figure 2. Electron micrograph of thin sections of cells of strain DSM 9103 grown with EDTA as sole source of carbon, nitrogen and energy (the bar represents $1 \mu \mathrm{m}$ ). 
succinate and fumarate as growth substrates. Subsequently, growth with succinate or fumarate as sole source of carbon and energy was also observed in batch culture when using bigger cultivation volumes.

The GC content of the EDTA-degrading isolate was $63.1 \mathrm{~mol} \%$. No menaquinones were found in strain DSM 9103 and the major ubiquinone was one with 10 isoprenoid units in the side chain (ubiquinone Q-10). This is indicative of a position of the strain in the $\alpha$-subclass of Proteobacteria. The polar lipid pattern suggests the strain to be a member of either the Paracoccus branch of the $\alpha$-subclass, or the Rhizobium and Agrobacterium group. Hydroxy fatty acids were not present and the predominant fatty acids were the ones comprised in 'summed feature 7' $(18: 1 \omega 7 c / \omega 9 t / \omega 12 t$ and $18: 1 \omega 7 c / \omega 9 c / \omega 12 t)$ with a portion of $67.63 \%$ followed by 19:0 cyclo $\omega 8 \mathrm{c}$ with $23.05 \%$.

The complete sequence of the 16S rRNA gene of DSM 9103 was determined by direct sequencing of the PCR amplified 16S rRNA DNA. The sequence was compared with the currently available sequences of members of the $\alpha$-subclass of Proteobacteria. Using only type strains for the various genera, the results are presented as phylogenetic tree (Figure 3) and similarity matrix (Table 1). Highest similarity was found between the $16 \mathrm{~S}$ rDNA sequences of strain DSM 9103 and members of the Mesorhizobium genus with $96.2 \%$ similarity between DSM 9103 and the type strain Mesorhizobium loti. Furthermore, the 16S rDNA sequence of DSM 9103 showed high similarity to the 16S rDNA of Aminobacter aminovorans and Chelatobacter heintzii $(95.7 \%$ similarity) and of Pseudoaminobacter salicylatoxidans $(95.6 \%$ similarity). As $C$. heintzii was proposed to be a synonym of Aminobacter aminovorans (Kämpfer et al. 2002) only the latter species is represented in the phylogenetic tree in Figure 3. However, 16S rDNA similarities were below the $97 \%$ mark requested for the affiliation of a new species to an existing genus. Hence, isolate DSM 9103 seems to belong to a new genus within the Rhizobiales order and, more precisely, within the Mesorhizobium/ Phyllobacterium group (family).

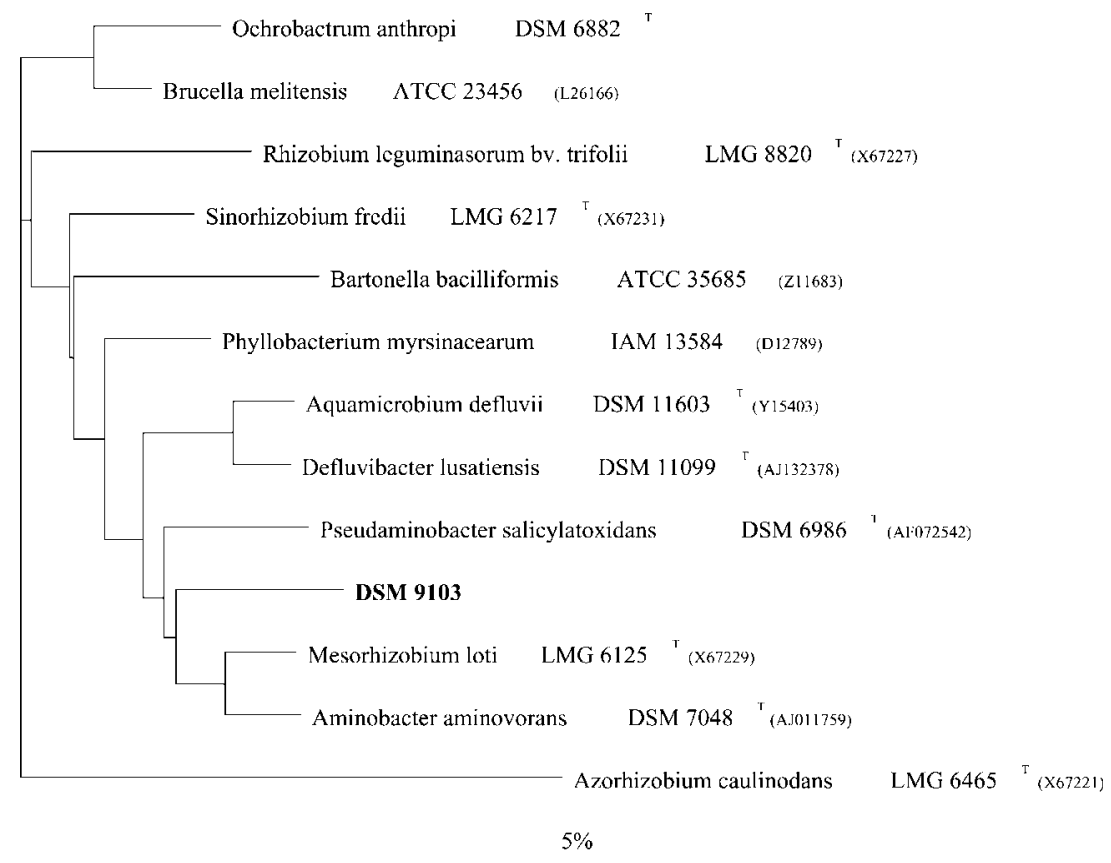

Figure 3. Dendrogram of type strains of the $\alpha$-subclass of Proteobacteria most closely related to the EDTA-degrading strain DSM 9103. Since similarities of greater than $99.6 \%$ were found between the 16S rDNA sequences of Aminobacter aminovorans and Chelatobacter heintzii (Kämpfer et al. 1999) and C. heintzii was reported to be a subjective synonym of A. aminovorans (Kämpfer et al. 2002), only the latter was included in the tree although both strains are still treated as two separate genera in the new edition of Bergey's manual. 
Table 1. Percentage similarities between 16S rDNA sequences from type strains of the genera Mesorhizobium, Aminobacter, Pseudoaminobacter and other members of the Rhizobiales order as well as the related EDTA-degrading isolate DSM 9103

\begin{tabular}{|c|c|c|c|c|c|c|c|c|c|c|c|c|c|}
\hline Strains & 1 & 2 & 3 & 4 & 5 & 6 & 7 & 8 & 9 & 10 & 11 & 12 & 13 \\
\hline 1. DSM 9103 & - & & & & & & & & & & & & \\
\hline 2. Mesorhizobium loti & 96.2 & - & & & & & & & & & & & \\
\hline 3. Pseudoaminobacter salicylatoxidans & 95.6 & 95.9 & - & & & & & & & & & & \\
\hline 4. Phyllobacterium myrsinacearum & 94.9 & 96.6 & 95.7 & - & & & & & & & & & \\
\hline 5. Aquamicrobium defluvii & 95.0 & 95.4 & 96.5 & 95.8 & - & & & & & & & & \\
\hline 6. Defluvibacter lusatiensis & 95.1 & 95.3 & 95.5 & 95.5 & 98.4 & - & & & & & & & \\
\hline 7. Sinorhizobium fredii & 94.9 & 95.1 & 94.7 & 96.0 & 94.9 & 95.3 & - & & & & & & \\
\hline 8. Aminobacter aminovorans & 95.7 & 98.0 & 96.9 & 96.6 & 95.7 & 95.2 & 95.0 & - & & & & & \\
\hline 9. Rhizobium leguminasorum bv. trifolii & 93.3 & 93.5 & 92.9 & 93.7 & 93.5 & 93.9 & 95.3 & 93.3 & - & & & & \\
\hline 10. Ochrobactrum anthropi & 93.3 & 93.8 & 92.7 & 94.4 & 92.9 & 94.2 & 94.9 & 93.7 & 94.3 & - & & & \\
\hline 11. Brucella melitensis & 94.3 & 94.4 & 93.8 & 95.5 & 94.4 & 95.5 & 96.0 & 94.2 & 94.6 & 97.4 & - & & \\
\hline 12. Bartonella bacilliformis & 93.0 & 93.8 & 92.8 & 95.1 & 93.8 & 94.0 & 94.9 & 93.5 & 93.4 & 93.4 & 95.0 & - & \\
\hline 13. Azorhizobium caulinodnas & 89.4 & 89.2 & 90.0 & 90.2 & 90.0 & 90.5 & 89.4 & 89.7 & 89.7 & 90.5 & 90.5 & 88.4 & - \\
\hline
\end{tabular}

\section{Influence of metal ions on the utilisation of EDTA}

Both in nature and in growth media used in this work powerful chelating agents such as EDTA are complexed with metal ions. Therefore, the influence of metal ion complexation on the utilisation of EDTA by strain DSM 9103 had to be considered.

The initial speciation of EDTA in the mineral medium employed for the cultivation of strain DSM 9103 was predicted with the help of the speciation prediction program ChemEQL (Müller 1996). Accordingly, EDTA (initial concentration of $1.5 \mathrm{~g} \mathrm{l}^{-1}$ ) should be mainly complexed with $\mathrm{Mg}^{2+}$ (58.3\% of total EDTA) and $\mathrm{Ca}^{2+}$ (41.1\% of total EDTA) (Witschel et al. 1999). This indicates that strain DSM 9103 is able to utilise EDTA when complexed with either $\mathrm{Mg}^{2+}$ or with $\mathrm{Ca}^{2+}$ or with both of them.

In a chemostat experiment residual EDTA concentrations were determined when the culture grew at $D=0.035 \mathrm{~h}^{-1}$ and was fed with a mineral medium containing approximately $1.5 \mathrm{~g} \mathrm{l}^{-1}$ EDTA. The residual concentrations were about $36 \mu \mathrm{M}$. Using a maximum specific growth rate with EDTA of $0.05 \mathrm{~h}^{-1}$ a half saturation constant $K_{\mathrm{s}}$ of approximately $15 \mu \mathrm{M}$ was estimated with the help of the Monod equation. This contrasts strongly with the apparent affinity constant of the EDTA transport system reported earlier for CaEDTA (Witschel et al. 1999) which was 30-40 times lower $\left(K_{\mathrm{t}}=0.4 \mu \mathrm{M}\right)$, suggesting that the culture should exhibit a higher affinity than reflected by the value obtained for $K_{\mathrm{s}}$. When using $K_{\mathrm{t}}$ as affinity constant in the Monod equation a residual EDTA concentration of about $1 \mu \mathrm{M}$ is predicted. Considering that the concentration of all heavy metal ions in the medium was $15-20 \mu \mathrm{M}$ one has to assume that most of the residual EDTA in the cultivation liquid was complexed with heavy metal ions and was therefore not available to the cells.

Since $\mathrm{Fe}^{3+}$ ions make up for the largest portion of all heavy metal ions in the medium employed we tested the utilisation of Fe(III)EDTA by strain DSM 9103 in an additional experiment. We focused on the degradability of Fe(III)EDTA for two further reasons. First, in the environment a large portion of EDTA may be complexed with $\mathrm{Fe}^{3+}$ ions (Kari 1994; Nowack 1996). For instance, in the influent of several Swiss municipal wastewater treatment plants the fraction of $\mathrm{Fe}(\mathrm{III}) \mathrm{EDTA}$ was found to range between $20 \%$ and $50 \%$, in the effluent it was even higher (40$80 \%$ ), and in the Swiss river Glatt the fraction amounted to 30\%. Second, EDTA-utilising Agrobacterium radiobacter ATCC 55002, was reported to be able to grow with Fe(III)EDTA only (Lauff et al. 1990) whereas EDTA-degrading strain BNC1 was found to be unable to use Fe(III)complexed EDTA (Henneken et al. 1995). To test whether strain DSM 9103 can degrade EDTA 
when added as Fe(III)-complex, Fe(III)EDTA was pulsed into a continuous culture of strain DSM 9103 growing at $D=0.025 \mathrm{~h}^{-1}$ and fed with a mineral medium containing $1.5 \mathrm{~g}^{-1}$ EDTA as sole source of carbon, nitrogen and energy. The initial concentration of the added Fe(III)EDTA was approximately $250 \mathrm{mg}^{-1}$. For comparison, a pulse of uncomplexed EDTA was added to a continuous culture growing at $D=0.015 \mathrm{~h}^{-1}$. Considering the excess of $\mathrm{Mg}^{2+}$ and $\mathrm{Ca}^{2+}$ in the mineral medium one can predict that the pulsed free EDTA was instantaneously complexed by $\mathrm{Mg}^{2+}$ or $\mathrm{Ca}^{2+}$ present in the culture medium.

The response of the culture was considerably different for the two pulses. In case of Fe(III)EDTA addition (Figure 4) the concentration of EDTA in the cultivation liquid remained more or less constant during the first few hours after the pulse and then started to increase. A comparison of measured EDTA concentrations with calculated wash-out and wash-in curves suggested that during the first hours after the pulse the EDTA continuously supplied to the culture from the medium reservoir was consumed whereas the extra Fe(III)EDTA was not utilised. Despite the ongoing consumption of the inflowing EDTA, the formation of biomass was immediately inhibited as indicated by the $\mathrm{OD}_{546}$ following the theoretical wash-out curve perfectly. After $4-5 \mathrm{~h}$, EDTA started to accumulate in the culture and wash-in of EDTA proceeded until $24 \mathrm{~h}$ after the pulse indicating an inhibition of the consumption of otherwise readily degradable EDTA complexes. The phenomenon that, after some time lag, the presence of Fe(III)EDTA exerts an inhibitory effect on the degradation of free EDTA has also previously been observed in degradation experiments with resting cells of DSM 9103 (Satroutdinov et al. 2000). After $24 \mathrm{~h}$ the measured EDTA concentrations dropped again below the theoretical wash-in curve. Hence, consumption of EDTA from the medium resumed before Fe(III)EDTA had been washed out completely finally resulting in regrowth of biomass.

In contrast, in case of a pulse of uncomplexed EDTA (data not shown) the comparison of the measured EDTA concentrations with the theoretical wash-out curve suggested immediate utilisation of the added EDTA. During the pulse, the measured DOC concentrations in the culture

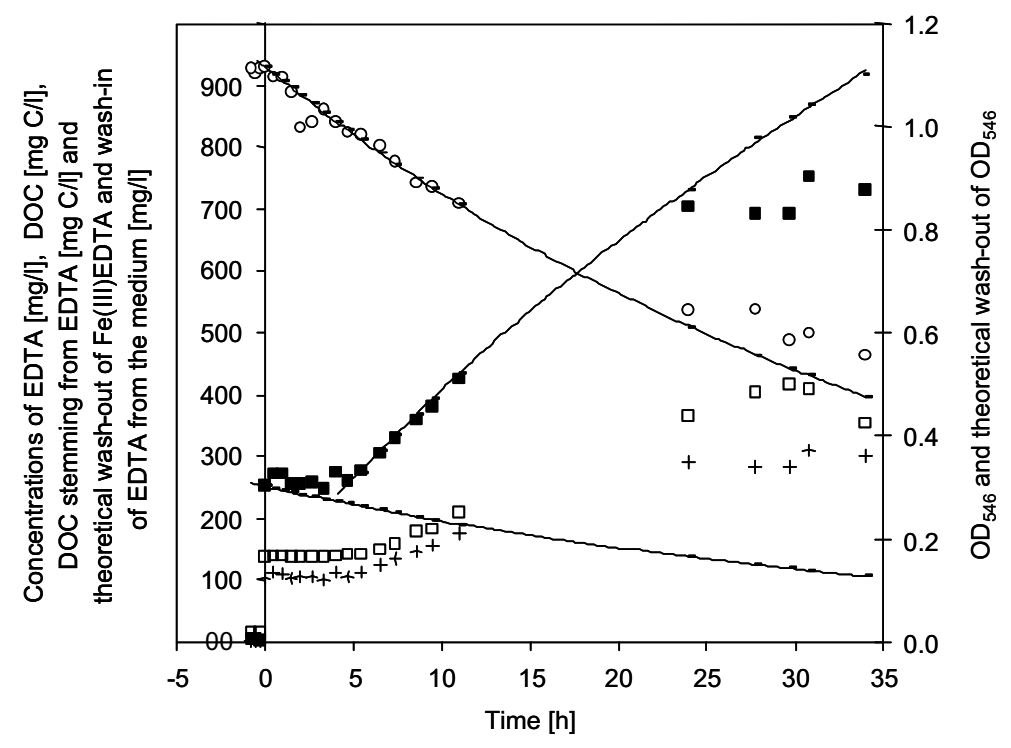

Figure 4. Pulse-wise addition of Fe(III)-complexed EDTA to a continuous culture of strain DSM 9103 growing with EDTA as sole source of carbon, nitrogen and energy $\left(D=0.025 \mathrm{~h}^{-1}\right)$. The Fe(III)EDTA pulse was introduced at $t=0 \mathrm{~h}$. As a function of time the biomass concentration was measured as $\mathrm{OD}_{546}(\mathrm{O})$ and compared to the theoretical washout curve (- - -) calculated under the assumption that the bacteria stopped consuming EDTA. Moreover, the EDTA concentration in the cultivation liquid (匚) was monitored and based on these values the DOC stemming from EDTA $(+)$ was calculated. The theoretical wash-out curve for the added Fe(III)EDTA (- - -) and the wash-in curve for EDTA (- - ) due to a stop of microbial EDTA degradation were also shown. Finally, the DOC $(\square)$ was followed during the experiment. 
always matched those of EDTA and therefore, the consumption of the pulsed EDTA was apparently not accompanied by the excretion of any metabolite. Degradation of EDTA led to the formation of additional biomass.

\section{Growth with complexing agents other than EDTA}

Several other complexing agents, all belonging to the group of aminopolycarboxylic acids, were assessed as growth substrates for strain DSM 9103 in batch culture in at least two experiments. Diethylenetriaminepentaacetate (DTPA) and hydroxyethylethylenediaminetriacetate (HEDTA), two other important and powerful chelating agents, did not support growth of strain DSM 9103. On the other hand, nitrilotriacetate (NTA) was utilised by the bacterium. However, growth with NTA was rather poor with respect to both the yield $Y_{\mathrm{x} / \mathrm{s}}$ and to the maximum specific growth rate $\mu_{\max }$ (Table 2). The known metabolites of EDTA and NTA breakdown, i.e. N,N'-EDDA and IDA, respectively, served also as growth substrates. IDA supported even rather fast growth of the strain, comparable with growth on the non-complexing agent fumarate (Table 2). N,N-EDDA a stereoisomer of N, $\mathrm{N}^{\prime}$-EDDA on the other hand was not utilised by the strain. Eventually, strain DSM 9103 grew with S,S-EDDS, a structural isomer of EDTA. Growth with S,S-EDDS was slightly faster than with EDTA and resulted in the highest amount of biomass produced per gram of complexing agent used. Only during growth with

Table 2. Maximum specific growth rates $\mu_{\max }$ and yields $Y_{\mathrm{x} / \mathrm{s}}$ during batch growth of strain DSM 9103 with different carbon and nitrogen sources

\begin{tabular}{lcl}
\hline Growth substrate & $\mu_{\max }\left(\mathrm{h}^{-1}\right)$ & $\begin{array}{l}Y_{\mathrm{X} / \mathrm{S}}(\mathrm{g} \mathrm{DW} \\
\left.(\mathrm{g} \text { substrate })^{-1}\right)\end{array}$ \\
\hline EDTA & $0.05 \pm 0.006$ & $0.26 \pm 0.01$ \\
[S,S]-EDDS & $0.067 \pm 0.001$ & $0.39 \pm 0.07$ \\
$\mathrm{NTA}$ & $0.0057 \pm 0.0$ & $0.11 \pm 0.02$ \\
$\mathrm{IDA}$ & $0.094 \pm 0.004$ & $0.31 \pm 0.0$ \\
$\mathrm{~N}, \mathrm{~N}^{\prime}$-EDDA & $0.059 \pm 0.003$ & $0.29 \pm 0.01$ \\
Fumarate $+\mathrm{NH}_{4}^{+}$ & $0.105 \pm 0.02$ & $0.38 \pm 0.0$ \\
\hline
\end{tabular}

Initial concentrations of the carbon/energy/(nitrogen) substrate were approximately $1.0 \mathrm{~g} \mathrm{l}^{-1}$ and that of $\mathrm{NH}_{4}^{+}$was $0.5 \mathrm{~g} \mathrm{l}^{-1}$. All values are averages of at least two independent growth experiments. fumarate a similar yield was observed. The EDDS molecule contains two chiral carbon atoms and, therefore, three optical isomers of EDDS exist, namely S,S-EDDS, R,R-EDDS and R,S-EDDS. Besides S,S-EDDS strain DSM 9103 utilised R,SEDDS but not R,R-EDDS.

Batch growth of strain DSM 9103 with mixtures of EDTA and an alternative substrate, in particular a second aminopolycarboxylic acid

To obtain some information on the regulation of EDTA degradation in the presence of other substrates strain DSM 9103 was cultivated under batch conditions with mixtures of EDTA and [S,S]-EDDS, NTA, IDA, N,N'-EDDA and fumarate. In all experiments cells were precultured with EDTA during two batch passages before inoculating them into the medium containing the substrate mixture (initial concentration of each substrate was about $0.5 \mathrm{~g}^{-1}$ ).

\section{Growth with EDTA/NTA}

During cultivation of strain DSM 9103 with the EDTA/NTA mixture a sequential utilisation pattern was observed with EDTA being used preferentially (Figure 5A). Nevertheless, in the initial growth phase with EDTA also approximately $100 \mathrm{mg}^{-1}$ NTA were utilised at a rate of $6.6 \mathrm{mg}$ NTA $(\mathrm{g} \mathrm{DW})^{-1} \mathrm{~h}^{-1}$. As soon as EDTA was close to exhaustion NTA utilisation proceeded at a higher rate of about $18.4 \mathrm{mg}$ NTA $(\mathrm{g} \mathrm{DW})^{-1} \mathrm{~h}^{-1}$. Most of the biomass was produced from EDTA while consumption of NTA resulted only in a very low increase in biomass concentration with a growth yield on NTA comparable to that found during growth of strain DSM 9103 with NTA only. The maximum specific growth rate on EDTA in the presence of NTA $\left(\mu_{\max }=0.033 \mathrm{~h}^{-1}\right)$ was significantly lower than that observed for growth with EDTA only $\left(\mu_{\max }=0.05-0.06 \mathrm{~h}^{-1}\right)$. This indicates a certain inhibitory effect of NTA exerted on growth with EDTA although NTA did not repress the utilisation of EDTA during mixed substrate cultivation.

\section{Growth with EDTA/N, $N^{\prime}-E D D A$}

Also in this case, EDTA was used first and only shortly before all EDTA had been consumed $\mathrm{N}, \mathrm{N}^{\prime}$-EDDA started to be degraded, initially with a comparably high rate, which then slowed down 

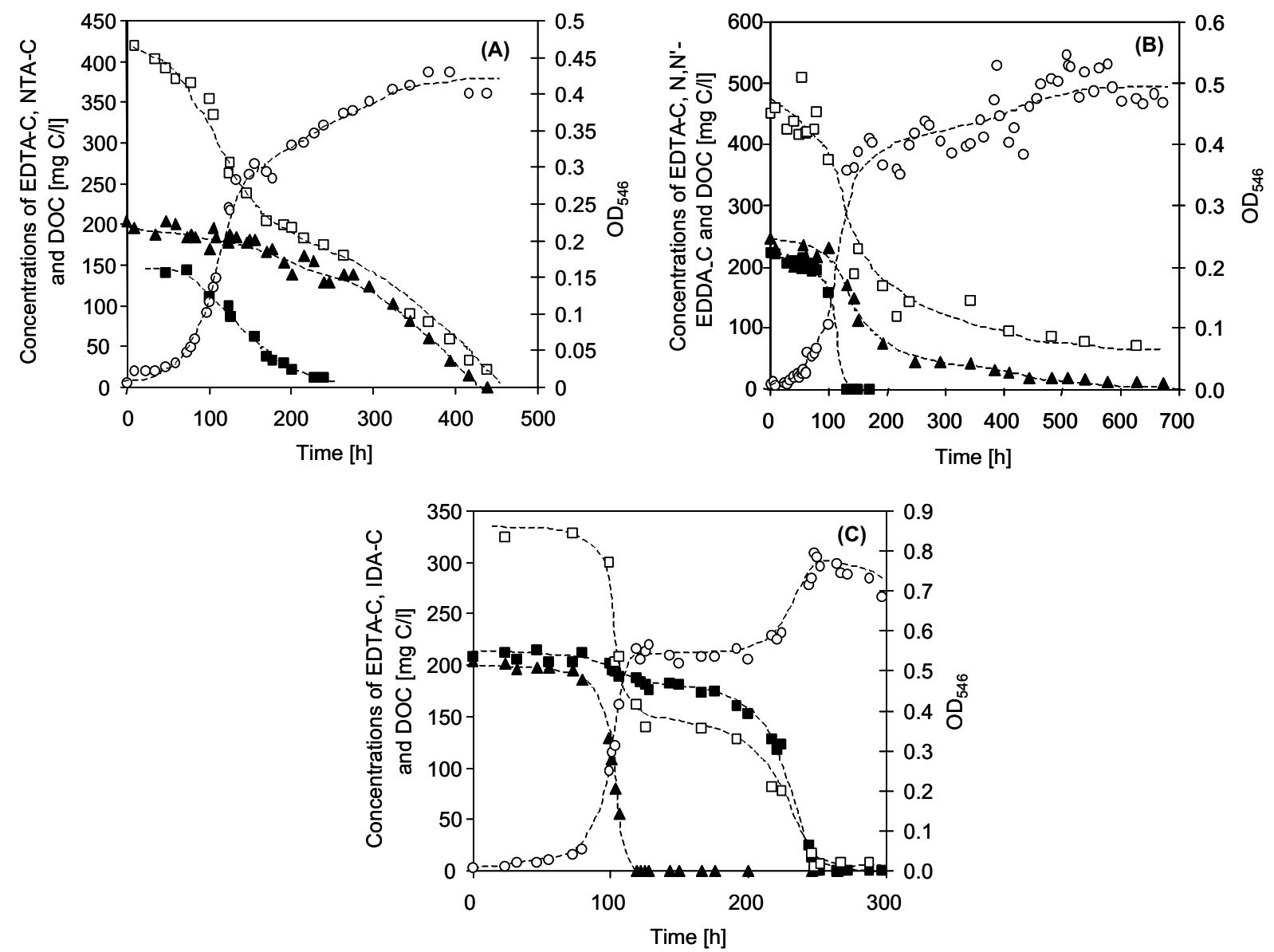

Figure 5. Growth of bacterial strain DSM 9103 with EDTA and a second substrate in batch culture. The biomass concentration, measured as $\operatorname{OD}_{546}(\mathrm{O})$, as well as the concentrations of EDTA-carbon $(\mathbf{\square})$, carbon from the second substrate $(\mathbf{\Lambda})$ and DOC are shown ( $\square$ ). (A) second substrate $=$ NTA, (B) second substrate $=$ N, $N^{\prime}$-EDDA, and (C) second substrate $=$ IDA.

significantly (Figure 5B). As in case of growth with EDTA/NTA most of the biomass produced throughout the whole cultivation period stemmed from the utilisation of EDTA and the maximum specific growth rate $\mu_{\max }$ during EDTA utilisation $\left(0.03 \mathrm{~h}^{-1}\right)$ was reduced in comparison to growth with EDTA only. A DOC balance considering EDTA and N,N'-EDDA suggests that during $\mathrm{N}, \mathrm{N}^{\prime}$-EDDA utilisation a product was formed and excreted into the medium. Consequently, biomass formation was very low during the slow degradation of $\mathrm{N}, \mathrm{N}^{\prime}$-EDDA.

\section{Growth with EDTA/[S,S]-EDDS}

During batch growth with this mixture both substrates were used and completed simultaneously supporting a maximum specific growth rate $\mu_{\max }$ of $0.04 \mathrm{~h}^{-1}$ during the exponential phase.
Growth with EDTA/IDA

The growth of the bacterial isolate DSM 9103 with a mixture of EDTA and IDA followed a diauxic pattern with IDA being the preferred substrate (Figure 5C). Nevertheless, a small fraction (about $10 \%$ ) of EDTA was already degraded during the phase of IDA utilisation. After growth with IDA which supported a maximum specific growth rate $\mu_{\max }$ of $0.08 \mathrm{~h}^{-1}$ the culture entered a lag phase of approximately 3 days before degradation of EDTA started and resulted in a second growth phase characterised by a $\mu_{\max }$ of $0.06 \mathrm{~h}^{-1}$.

\section{Growth with EDTA/fumarate}

These two substrates were consumed simultaneously during batch cultivation and growth proceeded at a maximum specific growth rate of 
$0.075 \mathrm{~h}^{-1}$. However, when fumarate was exhausted, the utilisation of EDTA still present in the growth medium stopped as well, Therefore, only about $50-60 \%$ of the initial EDTA were utilised within the time period analysed. Hence, fumarate had a positive effect on the degradation of EDTA but on the other hand EDTA breakdown seemed to become dependent on the presence of fumarate. This might indicate the necessity for reorganisation of the EDTA metabolism when growing with EDTA alone after growth with EDTA in the presence of an alternative, easily degradable substrate. As far as the catabolic pathway is known for this complexing agent in isolate DSM 9103 (Witschel 1999), it includes the initial investment of electrons and involvement of oxygen as co-substrate. One can speculate that cellular metabolism has to be reorganised because in presence of fumarate the electrons needed for substrate activation originate from the degradation of fumarate while during growth with EDTA alone they may come from the oxidation of downstream intermediates.

\section{Discussion}

So far, only two pure EDTA-degrading strains have been described in detail. Mainly based on physiological and biochemical tests one strain (ATCC 55002) was identified as Agrobacterium radiobacter sp. (Lauff et al. 1990; Palumbo et al. 1994), now renamed Rhizobium radiobacter (Young et al. 2001), whereas the data collected for the second strain (BNC1) allowed only its affiliation to the $\alpha$-subclass of Proteobacteria (Nörtemann 1992). Here, we present the isolation of a third EDTA-degrading bacterial strain and some of its physiological, biochemical, chemotaxonomic and phylogenetic characteristics.

The new isolate (strain DSM 9103) has several features in common with strain BNC1, for instance slow growth on both EDTA and other carbon sources and the fact that iron-complexed EDTA supports no growth. Both isolates are clearly distinct from the third strain, $R$. radiobacter sp., in particular with respect to the EDTA species used as growth substrate. In contrast to strain $\mathrm{BNC1}$ and DSM 9103 R. radiobacter is only able to grow with $\mathrm{Fe}(\mathrm{III})$ EDTA. No other EDTA species tested (free EDTA, NiEDTA, CuEDTA, Co(III)EDTA) supported growth (Palumbo et al. 1994). In case of DSM 9103 and BNC1 it has not been unravelled so far which EDTA species is/are really the growth substrates but the data available suggests that CaEDTA and other EDTA species with a rather low stability constant are the most likely species. First, the increase of the $\mathrm{Ca}^{2+}$ concentration in the mineral medium for DSM 9103 improved growth of the strain markedly. Second, experiments with resting cells of strain BNC1 and DSM 9103 showed that EDTA complexed with $\mathrm{Ca}^{2+}, \mathrm{Mg}^{2+}, \mathrm{Ba}^{2+}$, or $\mathrm{Mn}^{2+}$ were readily degraded (Klüner et al. 1998; Satroutdinov et al. 2000). All these complexes have a stability constant lower than $10^{16}$. For more stable EDTA complexes (complexes with $\mathrm{Co}^{2+}, \mathrm{Cu}^{2+}, \mathrm{Zn}^{2+}$ and $\left.\mathrm{Pb}^{2+}\right)$ the results indicated no direct utilisation but dissociation of the complexes prior to degradation (Satroutdinov et al. 2000). Third, uptake studies in strain DSM 9103 with ${ }^{45} \mathrm{Ca}^{2+}$ in the presence and absence of EDTA demonstrated that $\mathrm{Ca}^{2+}$ is transported together with EDTA into the cells (Witschel et al. 1999). In the uptake assays and the experiments with resting cells also free EDTA was transported/used. However, strain BNC1 did not grow with free EDTA and cell lysis caused by an excess of the uncomplexed chelating agent was suggested as the reason (Nörtemann 1992).

The proposed close taxonomic relationship of strain BNC1 and DSM 9103 is also supported by the fact that EDTA metabolism in both strains seems to be very similar if not identical. While EDTA transport has only been investigated in strain DSM 9103 (Witschel et al. 1999) the initial intracellular enzymatic steps in EDTA degradation were elucidated in both strains (Bohuslavek et al. 2001; Witschel et al. 1997): A monooxygenase consuming $\mathrm{FMNH}_{2}$ delivered by a $\mathrm{NADH}_{2}: \mathrm{FMN}$ oxidoreductase catalyses the oxidation of EDTA and the first intermediate of EDTA, ethylenediaminetriacetate (ED3A). Based on SDS PAGE similar molecular weights were estimated for the enzymes from both isolates and finally the $26 \mathrm{~N}$-terminal amino acids of the EDTA monooxygenases of both strains were identical.

Eventually, 16S rRNA sequence analysis revealed a rather high similarity of DSM 9103 with C. heintzii. The latter strain was originally isolated 
for its ability to degrade NTA (Auling et al. 1993; Egli et al. 1988) and it grows also with the aminopolycarboxylic acid IDA but not with EDTA or EDDS (Bucheli-Witschel \& Egli 2001). Interestingly, EDTA catabolism in strains DSM 9103 and BNC1 as well as the enzymes participating in EDTA degradation share many common characteristics with those found for the metabolism of NTA in C. heintzii (Egli 1994; Witschel et al. 1997). The sequence of the gene encoding EDTA monooxygenase in strain BNC1 was elucidated and showed the highest similarity/identity values $(46.2 \% / 37.8 \%)$ when compared with the NTA monooxygenase gene from $C$. heintzii (Bohuslavek et al. 2001).

An interesting observation is the fact that isolate DSM 9103 appeared in traditional substrate tests as a rather fastidious organism with an extremely restricted spectrum of carbon substrates that can be used. However, when cultivated in EDTA-limited continuous culture DSM 9103 was able to utilise and grow with a number of such 'non-growth' substrates when these were added as pulses. This suggests that the substrate utilisation spectra determined for isolates in the traditional way may not reflect the whole catabolic spectrum of an organism, in particular in case of slow growing bacteria. Thus, the extensive lists that can presently be found in Bergey's manual and similar taxonomy reference books may only reflect a fraction of the substrates that can be utilised by the genospecies listed.

Finally, batch cultivation of bacterium DSM 9103 with substrate mixtures gave first indications on the regulation of EDTA breakdown, a point of high importance if the strain is to be employed for the treatment of EDTA-containing wastewaters. Alternative substrates supporting a specific growth rate of strain DSM 9103 comparable to that with EDTA apparently do not repress EDTA utilisation totally when present in the medium. However, EDTA consumption stopped when these substrates were used up suggesting the necessity of an intracellular rearrangement to degrade EDTA only. This points to a rather low metabolic flexibility of strain DSM 9103, a property that might be a disadvantage for the application of DSM 9103 for industrial wastewater treatment processes because fluctuations in the composition of wastewater are the rule rather than the exception.

\section{Acknowledgements}

We are indebted to D. Gschwind (Ciba-Geigy, Schweizerhalle, Switzerland) for kindly supplying us with the EDTA-degrading mixed microbial consortium. We further thank Prof $H$. Zähner (University of Tübingen, Germany) for the generous gift of S,S-EDDS. Our thanks also go to E. Wehrli (ETH, Zürich, Switzerland) for the preparation of the electron micrographs of strain DSM 9103. This work was financially supported by a grant from BUWAL.

\section{References}

Alder AC, Siegrist H, Gujer W \& Giger W (1990) Behaviour of NTA and EDTA in biological wastewater treatment. Water Res. 24: 733-742

Auling G, Busse H-J, Egli T, El-Banna T \& Stackebrandt E (1993) Description of the gram-negative, obligately aerobic, nitrilotriacetate (NTA)-utilizing bacteria Chelatobacter heintzii, gen. nov., sp. nov., and Chelatococcus asaccharovorans, gen. nov., sp. nov. Syst. Appl. Microbiol. 16: 104-112

BMU: Bundesminister für Umwelt, Naturschutz und Reaktorsicherheit, Germany (1991) Erklärung zur Reduzierung der Gewässerbelastung durch EDTA

Bohuslavek J, Payne J, Liu Y, Bolton H \& Xun L (2001) Cloning, sequencing, and characterization of a gene cluster involved in EDTA degradation from the bacterium BNC1. Appl. Environ. Microbiol. 67: 688-695

Bucheli-Witschel M \& Egli T (2001) Environmental fate and microbial degradation of aminopolycarboxylic acids. FEMS Microbiol. Rev. 25: 69-106

Egli T (1988) (An)aerobic breakdown of chelating agents used in household detergents. Microbiol. Sci. 5: 36-41

Egli T (1994) Biochemistry and physiology of the degradation of nitrilotriacetic acid and other complexing agents. In: Ratledge C (Ed) Biochemistry of Microbial Degradation (pp 179-195). Kluwer Academic Publishers, Dordrecht

Egli T, Weilenmann HU, El-Banna T \& Auling G (1988) Gramnegative aerobic, nitrilotriacetate-utilizing bacteria from wastewater and soil. Syst. Appl. Microbiol. 10: 297-305

Gardiner J (1976) Complexation of trace metals by ethylenediaminetetraacetic acid (EDTA) in natural waters. Water Res. 10: $507-514$

Gschwind N (1992) Biologischer Abbau von EDTA in einem Modellabwasser. gwf Wasser Abwasser 133: 546-549

Henneken L, Klüner T, Nörtemann B \& Hempel DC (1994) Abbau von EDTA mit freien und immobilisierten Bakterien. gwf Wasser Abwasser 135: 354-358

Henneken L, Nörtemann B \& Hempel DC (1995) Influence of physiological conditions on EDTA degradation. Appl. Microbiol. Biotechnol. 44: 190-197

Henneken L, Nörtemann B \& Hempel DC (1998) Biological degradation of EDTA: Reaction kinetics and technical approach. J. Chem. Technol. Biotechnol. 73: 144-152 
Houriet J-P (1996) NTA dans les eaux. Cahier de l'environnement 264. Office fédéral de l'environnement, des forêts et du paysage (OFEFP), Berne, Switzerland

Jones PW \& Williams DR (2001) Speciation efficiency indices (SEI) and readily-biodegradable indices (RBI) for optimising ligand control of environmental and associated industrial processes. Int. J. Environ. Anal. Chem. 81: 73-88

Kaluza U, Klingelhöfer P \& Taeger K (1998) Microbial degradation of EDTA in an industrial wastewater treatment plant. Water Res. 32: 2843-2845

Kämpfer P, Müller C, Mau M, Neef A, Auling G, Busse H-J, Osborn AM \& Stolz A (1999) Description of Pseudoaminobacter gen. nov. with two new species, Pseudoaminobacter salicylatoxidans sp. nov. and Pseudoaminobacter defluvii sp. nov. Int. J. Syst. Bacteriol. 49: 887-897

Kämpfer P, Neef A, Salkinoja-Salonen MS \& Busse H-J (2002) Chelatobacter heintzii is a later subjective synonym of Aminobacter aminovorans. Int. J. Syst. Evol. Microbiol. 52: 835-839

Kari FG (1994) Umweltverhalten von Ethylendiamintetraacetat (EDTA) unter spezieller Berücksichtigung des photochemischen Abbaus. PhD thesis No. 10698, Swiss Federal Institute of Technology, Zürich, Switzerland

Kari FG \& Giger W (1996) Speciation and fate of ethylenediaminetetraacetate (EDTA) in municipal wastewater treatment. Water Res. 30: 122-134

Klopp R \& Pätsch B (1994) Organische Komplexbildner in Abwasser, Oberflächenwasser und Trinkwasser, dargestellt am Beispiel der Ruhr. Wasser \& Boden: 32-37

Klüner T (1996) Chemie und Biochemie des mikrobiellen EDTA-Abbaus. PhD thesis, Universität-Gesmthochschule Paderborn, Germany

Klüner T, Hempel DC \& Nörtemann B (1998) Metabolism of EDTA and its metal chelates by whole cells and cell-free extracts of strain BNC1. Appl. Microbiol. Biotechnol. 49: 194-201

Knobel H-R (1997) Genetic study of bacterial nitrilotriacetate degrading enzymes. PhD thesis No. 12146, Swiss Federal Institute of Technology, Zürich, Switzerland

Könen I (1997) Bestimmung von EDTA-Ersatzstoffen auf Aminopolycarbonsäurebasis. PhD thesis, TH Aachen, Germany

Kovaleva IB, Mitrofanova ND \& Martynenko LI (1992) The structure of transition metal complexonates derived from ethylenediamine-(N, $\left.\mathrm{N}^{\prime}\right)$-disuccinic acid. Russ. J. Inorg. Chem. 37: 41-45

Lauff JJ, Steele DB, Coogan LA \& Breitfeller JM (1990) Degradation of the ferric chelate of EDTA by a pure culture of an Agrobacterium sp. Appl. Environ. Microbiol. 56: 33463353

Müller B (1996) ChemEQL: A program to calculate chemical speciation equilibria, titrations, dissolutions, precipitation, adsorption, simple kinetics, and $\mathrm{pX}-\mathrm{pY}$ diagrams. Kastanienbaum, Switzerland

Nörtemann B (1992) Total degradation of EDTA by mixed cultures and a bacterial isolate. Appl. Environ. Microbiol. 58: 671-676

Nowack B (1996) Behaviour of EDTA in groundwater - a study of the surface reactions of metal-EDTA complexes. PhD thesis No. 11392, Swiss Federal Institute of Technology, Zürich, Switzerland
Palumbo AV, Lee SY \& Borman P (1994) The effect of media composition on EDTA degradation by Agrobacterium sp. Appl. Biochem. Biotechnol. 45/46: 811-822

Pfennig N, Widdel F \& Trüper HG (1981) The dissimilatory sulfate-reducing bacteria. In: Starr MP, Stolp H, Trüper HG, Balows H \& Schlegel HG (Eds) The Prokaryotes, Vol 1 (p 931). Springer Verlag, Berlin

Potthoff-Karl B, Greindl T \& Oftring A (1996) Synthese abbaubarer Komplexbildner und ihre Anwendung in Waschmittel- und Reinigungsformulierungen. SÖFW-J. 122: 392397

Satroutdinov AD, Dedyukhina EG, Chistyakova TI, Witschel M, Minkevich IG, Eroshin VK \& Egli T (2000) Degradation of metal EDTA complexes by resting cells of the bacterial strain DSM 9103. Environ. Sci. Technol. 34: 1715-1720

Saunamäki R (1995) Treatability of wastewaters from totally chlorine-free bleaching. Tappi J. 78: 185-192

Scheiner D (1976) Determination of ammonia and Kjeldahl nitrogen by indophenol method. Water Res. 10: 31-36

Schneider RP, Zürcher F, Egli T \& Hamer G (1988) Determination of nitrilotriacetate in biological matrices using ion exclusion chromatography. Anal. Biochem. 173: 278-284

Sykora V, Pitter P, Bittnerova I \& Lederer T (2001) Biodegradability of ethylenediamine-based complexing agents. Water Res. 35: 2010-2016

Uetz TA (1992) Biochemistry of nitrilotriacetate degradation in obligately aerobic, Gram-negative bacteria. $\mathrm{PhD}$ thesis No. 9722, Swiss Federal Institute of Technology, Zürich, Switzerland

Wanner U, Kemmler J, Weilenmann H-U, Egli T, El-Banna T \& Auling G (1990) Isolation and growth of a bacterium able to degrade nitrilotriacetic acid under denitrifying conditions. Biodegradation 1: 31-41

Witschel M (1999) Biochemical and physiological characterisation of a bacterial isolate able to grow with EDTA and other aminopolycarboxylic acids. PhD thesis No. 12967, Swiss Federal Institute of Technology, Zürich, Switzerland

Witschel M \& Egli T (1998) Purification and characterization of a lyase from the EDTA-degrading bacterial strain DSM 9103 that catalyzes the splitting of [S,S]-ethylenediaminedisuccinate, a structural isomer of EDTA. Biodegradation 8: 419428

Witschel M, Egli T, Zehnder AJB, Wehrli E \& Spycher M (1999) Transport of EDTA into cells of the EDTA-degrading strain DSM 9103. Microbiology 154: 973-983

Witschel M, Nagel S \& Egli T (1997) Identification and characterization of the two-enzyme system catalyzing the oxidation of EDTA in the EDTA-degrading bacterial strain DSM 9103. J. Bacteriol. 179: 6937-6943

Wolf K \& Gilbert PA (1992) EDTA-Ethylenediaminetetraacetic acid. In: Hutzinger $\mathrm{O}(\mathrm{Ed})$ The Handbook of Environmental Chemistry, Vol 3 (pp 243-259). Springer, Berlin Heidelberg

Young JM, Kuykendall LD, Martinez-Romero E, Kerr A \& Sawada H (2001) A revision of Rhizobium, with an emended description of the genus, and the inclusion of all species of Agrobacterium and Allorhizobiuzm undicola as new combinations: Rhizobium radiobacter, $R$. rhizogenes, $R$. rubi, $R$. undicola and R. vitis. Int. J. Syst. Evol. Microbiol. 51: 89103 